\title{
A IMPORTÂNCIA DA ASSISTÊNCIA TÉCNICA E EXTENSÃO RURAL (ATER) E DO CRÉDITO RURAL PARA A AGRICULTURA FAMILIAR EM GOIÁS
}

\author{
THE IMPORTANCE OF TECHNICAL ASSISTANCE AND RURAL EXTENSION \\ (ATER) AND RURAL CREDIT FOR FAMILY FARMING IN GOIÁS
}

\author{
L'IMPORTANCE D'ASSISTANCE TECHNIQUE ET EXTENSION RURAL \\ (ATER) ET CREDIT RURAL POUR LA AGRICULTURE FAMILIER EN GOIÁS
}

\author{
Guilherme Resende Oliveira - EMATER - Goiânia - Goiás - Brasil \\ resendego@gmail.com \\ Fernando Moreira de Araújo - EMATER - Goiânia - Goiás - Brasil \\ fernandomsbl@gmail.com \\ Carlos César de Queiroz - EMATER - Goiânia - Goiás - Brasil \\ carloscesar@emater.go.gov.br
}

\begin{abstract}
Resumo
0 estudo analisa duas importantes políticas públicas, a ATER e o Programa Nacional de Fortalecimento da Agricultura Familiar (PRONAF), além de verificar sua inter-relação. Ambas têm um importante papel no desenvolvimento econômico e regional, além do bem-estar dos agricultores familiares. 0 objetivo geral é traçar o perfil de agricultores familiares de Goiás, identificando as variáveis que influenciam 0 acesso ao crédito disponibilizado pelo programa, com destaque para a ATER e a sua principal instituição no estado de Goiás, a Agência Goiana Assistência Técnica, Extensão Rural e Pesquisa Agropecuária (Emater). Além disso, levantam-se novas evidências sobre 0 efeito dessas políticas na economia goiana. A baixa escolaridade do agricultor familiar, a concentração de serviços públicos e das atividades econômicas são fatores que justificam a atuação do extensionista rural e, consequentemente, a contribuição da ATER para reduzir a desigualdade regional. A ATER é mais demandada pelas atividades agropecuárias, correspondendo a $66 \%$ (78.879) dos atendimentos realizados. Em 2016, das 5.927 Declaração de Aptidão (DAPs), quase dois terços foram elaboradas para os próprios donos da propriedade. Em relação ao PRONAF, a pecuária se destaca representando $96,8 \%$ de todos os recursos financiados em 2016 , chegando a um volume de $\mathrm{R} \$ 335$ milhões em mais de 6,4 mil contratos, enquanto a agricultura teve quase $\mathrm{R} \$ 11$ milhões dos recursos aplicados.

Palavras-chave: Políticas Públicas, Agropecuária, Emater, PRONAF.
\end{abstract}

\section{Abstract}

The study analyses two public policies, the ATER and PRONAF, besides reviewing their interrelation. Both play an important role in economic and regional development, as well as the well-being of family farmers. The general objective is to outline the profile of the family farmers of Goiás, identifying the variables that influence the access to available credit by the program, with emphasis on ATER and its main institution in the state of Goiás, the Emater. In addition, new evidence is emerging about the effect of these policies on the economy of Goiás. The low level of education of the family farmer, a concentration of public services and the economic activities are the factors that justify a rural extension action and, consequently, the contribution of ATER in the reduction of regional inequality. The ATER is more demanded for agricultural activities, corresponding to 
$66 \%(78,879)$ of the services performed. In 2016, nearly two-thirds of 5,927 DAPs were made for the property owners. Regarding PRONAF, livestock stands out representing $96.8 \%$ of all resources financed in 2016, reaching a volume of $R \$ 335$ million in more than 6,4 thousand contracts, while agriculture had almost $R \$ 11$ million of the resources.

Keywords: Public Policy; Agriculture and Livestock; Emater, PRONAF.

\section{Résumé}

L'étude analyse deux importantes politiques publiques, ATER et PRONAF, en plus de vérifier leurs relation. Les deux jouent un rôle important dans le développement économique et regional en plus des le bien-être des agriculteurs. L'objectif général est d'établir un profil des agriculteurs familiaux de Goiás, d'identifier les variables qui influencent sur l'accès au crédit fourni par le programme, en particulier par la ATER, l'institution au premier plan dans l'Etat de Goiás, Emater. De plus, susciten des nouvelles évidences sur les effets de ces politiques dans l'économie goiannaise. Le bas niveau d'éducation de l'agriculteur familial, la concentration des services publique et les activités économiques sont des facteurs qui justifient les actions de l'assistance rural et par conséquent la contribution de l' ATER pour réduire l'inégalité régionale. La ATER est plus demandé par les activités agricoles, ce qui correspondent à 66\% (78.879) des visites effectuées. En 2016, 5.927 des DAPs, près des deux tiers ont été préparés pour les propriétaires agricoles. Par rapport à PRONAF, lélevage s'est détaché représentant $96,8 \%$ de toutes les ressources financées en 2016, atteignant le chiffre de $R \$ 335$ millions, dans plus de 6.4 mille contrats, alors que l'agriculture avait presque $\mathrm{R} \$ 11$ millions des ressources appliquées.

Mots- clés: Politiques Publiques, Élevage, Emater, PRONAF.

\section{Introdução}

O crédito rural é um dos principais instrumentos de intervenção governamental pertencente à política agrícola brasileira. O Sistema Nacional de Crédito Rural (SNCR) foi institucionalizado por meio da Lei 4829/1965 e tem o Banco do Brasil (BB) como um dos maiores agentes financeiros, além das demais instituições que compõem o sistema, a exemplo do Banco Nacional de Desenvolvimento Econômico e Social (BNDES), bancos privados e cooperativas de crédito. O Manual de Crédito Rural (MCR) contém a legislação vigente, que é publicada pelo Banco Central do Brasil (BC). A política de crédito rural permitiu que os agricultores adquirissem os instrumentos necessários à dinamização da produção, contudo, essa aquisição foi seletiva e induziu a um processo de modernização desigual, privilegiando algumas atividades, tipo de produtores e regióes.

Souza e Caume (2008) mostram que, desde a instituição do SNCR, houve um crescimento vertiginoso da disponibilidade de crédito. As mesmas variáveis que influenciaram sua expansão levaram a algumas retrações em determinados períodos, a exemplo do volume de depósitos à vista, taxas de inflação e de juros, os quais afetam diretamente a oferta de crédito. Apesar da redução da presença do Estado na década de 1990 
no financiamento das atividades produtivas e na política de crédito rural, algumas mudanças institucionais, permitiram substituir as fontes de financiamento público pelo privado. Assim, parte dos agricultores familiares se manteve alijado do processo de modernização agrícola, com menor acesso às inovações e ao mercado.

Assim sendo, foi criado o PRONAF, o primeiro programa de crédito específico para a agricultura familiar. Anteriormente, o recurso voltado para os pequenos agricultores provinha do Programa de Crédito Especial para Reforma Agrária (PROCERA), restrito aos beneficiários do Programa de Reforma Agrária. O PRONAF se tornou a principal política de financiamento à agricultura familiar, portanto, um importante instrumento de apoio a esse grupo. Desde 2002, o PRONAF já investiu mais de R $\$ 4,8$ bilhões em Goiás. Apenas no ano de 2016, foram aplicados no Estado mais de R\$ 340 milhões em 6 mil operações. No Centro-Oeste, ao todo, foram investidos quase R $\$ 1$ bilhão em 25 mil financiamentos. Ao total, no Brasil, foram financiados mais de R\$ 15 bilhões.

Melo e Resende Filho (2017) afirmam ser alta a interferência estatal no que diz respeito à concessão do crédito rural no Brasil. Por outro lado, o setor público é o maior responsável por ofertar esse tipo de recurso. De acordo com os autores, em 2011, apenas os Fundos Constitucionais de Financiamento contribuíram com $20 \%$ do total de recursos do crédito rural. Vale ressaltar que no Estado, o Fundo Constitucional de Financiamento do Centro-Oeste (FCO) é um dos principais provedores de recursos do PRONAF.

Gazolla e Schneider (2013) mostram que desde a criação do PRONAF houve uma expressiva queda na taxa de juros praticada e o aumento no dispêndio de recursos, além das inúmeras mudanças no seu marco legal e, consequentemente, no seu funcionamento. Tudo isso contribuiu para o fortalecimento dos agricultores, que tornaram suas propriedades mais diversificadas interna e setorialmente.

Contudo, todo esse financiamento não chega facilmente ao agricultor familiar. Nesse sentido, o assistente técnico/extensionista cumpre um importante papel para o programa. Ao longo da sua história, a atuação do serviço de extensão rural esteve contemporânea com as modificações e especializações do crédito rural. É uma das instituições com maior vivência em crédito rural tecnificado. Ademais, programas como o PRONAF foram elaborados com base nas reflexões de parte de extensionistas e outros atores. 
De modo geral, esse estudo avalia a contribuição da Assistência Técnica e Extensão Rural, doravante ATER, para o PRONAF no estado de Goiás na última década, com ênfase no ano de 2016, identificando, especialmente o papel da Emater de Goiás no acesso ao crédito. Além disso, verifica-se a relação entre o crédito rural e o desenvolvimento regional.

\section{Breve histórico do crédito rural e da ATER em Goiás}

Atualmente, a Emater é a instituição que herdou a missão da Associação de Crédito e Assistência Rural (ACAR), criada em 1959, em Goiás. Como o próprio nome mostra, era uma associação que atuava com dois instrumentos: crédito e assistência rural. O crédito rural em bases técnicas ou como assistência para uso pelos agricultores era uma novidade no Brasil de então, na concepção que trouxe. Naquela época, a agricultura e as tecnologias em uso demandavam capital, seja para a produção de café, cana, cacau, ou mesmo arroz, feijão, milho, mandioca ou criação de gado para leite e transporte (carro de boi), essas últimas típicas dos "pequenos agricultores", como eram chamados.

Segundo Queiroz (2004), a maioria dos agrônomos e veterinários vivia próxima ao litoral, mas a agricultura era praticada em todo o Brasil. Foi a implantação do serviço de extensão rural que interiorizou esses e outros profissionais de ciências agrárias e da área social no Brasil, permitindo o avanço da tecnificação no meio rural, principalmente nas atividades ligadas à agropecuária. A primeira turma a formar agrônomos e veterinários, em Goiás, foi em 1966. A ACAR Goiás funcionava há sete anos e, portanto, contava com uma estrutura de profissionais formados em outras regiões do país, a maioria deles de universidades do Rio de Janeiro (Escola Nacional de Agronomia e Escola Nacional de Veterinária) e de Minas Gerais (Escola de Agronomia de Viçosa e Escola de Veterinária da Universidade Federal de Minas Gerais), além de técnicos agrícolas de diferentes escolas do Brasil. As assistentes sociais se capacitavam para o tipo de trabalho que iam exercer no serviço de extensão rural. Eles trouxeram costumes, hábitos, maneiras de agir, vestir, falar e outros para o interior brasileiro.

De acordo com Souza e Caume (2008), um dos objetivos da extensão rural é a melhoria da agricultura. Para isso, um dos principais instrumentos 
é o crédito rural supervisionado. Os extensionistas eram preparados nos chamados cursos de "pré-serviço" ministrados, principalmente, no Centro de Treinamento de Extensão Rural em Viçosa, com duração de no mínimo três meses intensivos. Vale registrar que lá eram preparados para, entre outros ensinamentos, elaborarem os projetos técnicos de crédito rural supervisionado.

A ACAR era uma associação privada, sem fins lucrativos, que tinha por objetivo o desenvolvimento do rural, com a filosofia de ajudar o agricultor a ajudar a si mesmo. A associação mantinha-se com a captação de recursos de entidades parceiras, tais como o governo e parceria com agentes do agronegócio, de associações que se beneficiavam dos serviços por ela prestados e mesmo de prestação de serviços por meio do crédito rural.

Foi da iniciativa da extensão rural brasileira a implantação do crédito rural supervisionado no Brasil (Ribeiro, 2000). Vale destacar que era uma associação de assistência no sentido mais “lato", ou seja, possibilitava o financiamento de acordo com as necessidades levantadas daqueles que vivam no meio rural, daí a área social. O instrumento de crédito rural supervisionado permitia a elaboração de projetos em que se financiava desde galinhas, matrizes e reprodutores bovinos, como também uma máquina de costura para que a esposa do agricultor pudesse trabalhar ou confeccionar roupas para uso da família e comercialização, até investimentos. Financiava-se fossa séptica, filtro de água (saneamento básico, que até hoje é uma política deficiente no meio rural), além do jovem rural atendido nos chamados clubes $4 \mathrm{~S}$ (saber, sentir, servir, saúde) (Souza; Oliveira; Coelho, 2016).

O pequeno produtor era considerado quase marginal, o que tornava - do ponto de vista bancário - as operações muito arriscadas (Oliveira, 1984). Havia dificuldade de aceitação do crédito rural supervisionado, pois o banco entendia que os agricultores não tinham capacidade de pagamento. Além disso, era alto o custo para se financiar um pequeno, sendo que o processo era o mesmo para o grande e o pequeno, o qual tinha um retorno menor.

A atuação do serviço de extensão rural iniciava com a elaboração do projeto de crédito rural, com um diagnóstico da propriedade e das fontes de renda do agricultor. Depois de liberado os recursos, eram feitas três supervisões de acompanhamento de execução dos projetos. Dessas supervisões, eram feitos relatórios encaminhados a ACAR e ao banco 
financiador. O banco remunerava por este serviço, que era derivado da ação de supervisão. Esse tema foi motivo de muita polêmica, pois se afirmava que a extensão servia mais ao banco que ao agricultor. A extensão da ACAR Goiás tinha fins educativos, o que em alguns casos propiciava uma alta taxa de inadimplência (Oliveira, 1984), conforme avaliação feita pela Empresa Brasileira de Assistência Técnica e Extensão Rural (Embrater). Vale ressaltar que, com a Lei do crédito rural Lei 4.829/1965, o crédito rural orientado e supervisionado tinha que ter acompanhamento de profissional habilitado.

Com a estatização da ACAR, transformando-a em Empresa de Assistência Técnica e Extensão Rural, doravante Emater, houve, no entendimento de alguns, involução institucional - sai da área privada e acomoda-se na área pública - deixando de servir à demanda dos clientes, para atender a projetos governamentais. Assim, aconteceu uma sutil mudança: a ACAR era de assistência e a Emater de assistência técnica (Santana; Miziara, 2006). Então mais especializada em tecnologia, daí o início do abandono dos trabalhos da área social. O crédito rural supervisionado deixa de ter a importância que tinha e o orientado, específico para cultivos e criações, crescendo em volume.

A atuação da Emater, então praticada pela ACAR, era realizada em convênios com bancos estaduais e caixas econômicas. Pereira e Duarte (2004) apresentam a aplicação dos recursos de crédito rural pela ACAR Goiás, em 1975, com as seguintes entidades financeiras: Banco do Brasil, Banco de Crédito Real de Minas Gerais, Banco do Estado de Goiás, Banco Agropecuário de Goiás, Banco do Estado de Minas Gerais e Caixa Econômica do estado de Goiás, com as especificações em custeio e investimentos.

As análises acadêmicas tomaram corpo na década de $80 \mathrm{com}$ enfoque na capitalização do campo e associação do crédito e assistência técnica, cuja abordagem de atrelamento entre os dois não era uma boa associação, quando a maioria das tecnologias disponibilizadas para os agricultores são demandadoras de capital. Oliveira (1984) conclui que o crédito rural passou a ser um fim em si mesmo em detrimento da parte técnica, que ficava prejudicada. A então Embrater, coordenadora do Sistema Brasileiro de Assistência Técnica e Extensão Rural (Sibrater), discute o assunto com a preocupação da parte técnica, que é enfocada por projetos técnicos de difusão de tecnologia. 
Com a extinção da Embrater na década de 90, o serviço de extensão rural passa por momentos de desestruturação nos Estados até os dias de hoje. Em Goiás, não foi diferente. Primeiro a junção com a pesquisa, que já era prática em outros Estados e no mundo, depois a ela foram incorporadas fiscalização e política agrária. Em outra mudança institucional vira autarquia, depois administração direta, empresa pública e, finalmente hoje, autarquia especial. Mesmo com toda esta conturbação institucional não deixou de atender parte da demanda com crédito rural.

$\mathrm{Na}$ quase totalidade dos projetos nacionais de desenvolvimento e nas linhas de crédito, o serviço de extensão rural e de assistência técnica esteve e está presente, como na época dos principais programas de desenvolvimento, a exemplo do Projeto Manejo dos Recursos Naturais da Várzea (ProVárzea), Programa de Fomento da Pequena Indústria Rural (PROFIR), Programa de Redistribuição de Terras e de Estímulo à Agroindústria do Norte e do Nordeste (Proterra), Programa de Desenvolvimento dos Cerrados (POLOCENTRO) e, atualmente, Agência Especial de Financiamento Industrial (FINAME), Fundo Constitucional de Financiamento do Centro-Oeste (FCO), entre outros.

\section{Programa de Fortalecimento da Agricultura Familiar}

Apesar de Graziano Silva (1997) não tratar especificamente sobre o PRONAF, seu estudo aborda o Novo Rural Brasileiro e chama atenção para a figura do novo agricultor familiar. Esse novo agricultor, muitas vezes, passou a trabalhar em regime parcial de tempo, dividindo suas atividades no campo com outras tipicamente urbanas, o que influenciou (ou não) na sua produção agrícola e no autoconsumo no segmento da agricultura familiar. Além disso, o estudo ressalta alguns fatores diretamente relacionados ao programa, como o desvio de finalidade dos recursos do crédito rural e nova dinâmica populacional do meio rural.

Carneiro (1997) faz considerações acerca de noções subjacentes aos princípios que nortearam a formulação do PRONAF na agricultura familiar, verificando que a política de crédito agrícola brasileira no pósguerra se orientou para a modernização econômica e tecnológica da grande produção, tornando a pequena propriedade preterida. Além disso, ele salienta a necessidade da implementação de medidas que organizem o mercado e garantam preço para a agricultura familiar. 
Guanziroli (2007) ressalta alguns fatores que influenciaram negativamente a geração e renda pelos tomadores do PRONAF. Entre eles destacam-se a falta de assistência técnica ou baixa qualidade dela. Neste caso, o autor chama a atenção para os escritórios locais (em vários casos, responsabilidade das Emater's ou similares) que contam com poucos técnicos com o objetivo de dar orientação para uma área de abrangência de vários municípios, com um público alvo de milhares agricultores. Isso sem contar a falta de visão sistêmica dos técnicos. Outros fatores que diminuem a efetividade do programa, apontados pelo estudo, são as dificuldades no gerenciamento dos recursos do crédito e a falta de integração nos mercados, de estrutura de comercialização e de agregação de valor.

Navarro (2010) narra como foi a discussão sobre a elaboração do PRONAF e, antes disso, a incorporação do termo agricultura familiar na literatura nacional, bem como nas políticas agrícolas elaboradas na década de 90. O estudo ainda apresenta os entraves à implementação do PRONAF, bem como as particularidades empíricas, que dificultam abarcar toda a heterogeneidade dos milhões de casos ao grupo, nomeado pela expressão agricultor familiar.

Gazolla e Schneider (2013) estudam o uso do PRONAF no Rio Grande do Sul (RS), onde a maior parte do recurso vai para o Custeio Agrícola, com destaque para o milho e soja. Eles ainda evidenciam que o financiamento vem sendo usado com fertilizantes químicos, agrotóxicos, sementes melhoradas, máquinas agrícolas e até sementes geneticamente modificadas.

Feijó (2014) examina os custos, diretos e indiretos, associados à iniciativa de se fornecer financiamento barato a um segmento específico do setor rural. O trabalho aponta que o destino do financiamento está bem distribuído entre custeio e investimento, apesar do tamanho médio dos contratos serem relativamente grandes e os pobres rurais não possuírem uma participação significativa nas iniciativas de crédito.

Por fim, Eusébio, Maia e Silveira (2016) aplicam a metodologia de propensity score matching para mostrar que o acesso ao programa gerou um impacto positivo e significante no valor da produção, sendo que esse foi menor nas regióes menos desenvolvidas. Para regiões mais desenvolvidas, onde os agricultores são mais especializados e integrados ao mercado, o PRONAF teve efeitos ainda mais relevantes sobre o valor produzido. 


\section{Material e métodos}

Esta pesquisa faz uma análise descritiva das principais variáveis de interesse, isto é, da distribuição de recursos do PRONAF e da ATER pela Emater, principal instituição que presta o serviço aos agricultores familiares tomadores do PRONAF, por meio dos técnicos das unidades locais e que, portanto, têm acesso a uma série de informações relevantes do contexto.

Entre as variáveis utilizadas neste estudo sobre o PRONAF está o número de operações por município e os valores dos recursos distribuídos, todas provenientes das bases do Banco do Brasil e do Ministério da Integração Nacional (CONDEL/SUDECO). As informações sobre os agricultores familiares foram levantadas a partir dos sistemas internos da Emater de Goiás. As demais variáveis são procedentes de bases públicas, a exemplo do Instituto Brasileiro de Geografia e Estatística (IBGE), i.e. Pesquisa Agrícola Municipal (PAM) e Pesquisa Pecuária Municipal (PPM).

Além disso, são apresentadas informações que podem ajudar a estimar a demanda potencial de crédito por meio da "Declaração de Aptidão” ao PRONAF (DAP), as quais revelam o número de agricultores familiares do município. A concentração espacial, mais especificamente nos municípios, pode ser verificada por meio de diversos modelos ou índices. Contudo, neste trabalho será mostrada por meio dos mapas temáticos.

Além da análise estatística realizada, este estudo também executou a análise documental das principais normativas do financiamento rural, em especial do PRONAF. Naturalmente, nem todas foram explicitadas aqui. Algumas foram brevemente analisadas, sendo que as demais estão listadas na seção de referências deste trabalho.

\section{Resultados e discussão}

\section{Agricultura familiar em Goiás}

A agricultura familiar tem um papel relevante na economia. Guilhoto et al. (2006) estimaram o Produto Interno Bruto (PIB) do agronegócio familiar, o qual diz respeito à agropecuária familiar e as cadeias produtivas interligadas a essa, que correspondia a mais de $10 \%$ do PIB brasileiro em 2003 ou um terço do agronegócio brasileiro. 
A legislação mais recente sobre a Declaração de Aptidão (DAP) ao PRONAF é a Portaria No 234/2017, a qual estabelece as condições e procedimentos gerais para a emissão da DAP. Essa define as Unidades Familiares de Produção Rural do Grupo "B” como aquelas com renda bruta familiar anual de até R \$20.000,00. No estado de Goiás, em 2016, apenas 6,0\% das DAPs emitidas pela Emater foram para esse grupo. Assim, conclui-se que uma pequena parcela dos agricultores familiares possui pouca e nenhuma condição de tomarem o crédito rural. Os demais estão classificados no Grupo "V” e recebem até R\$ 360 mil, logo, é um público potencial para recebem o financiamento do PRONAF.

Além disso, a Portaria supracitada também identifica os agricultores familiares por finalidades em diferentes públicos, os quais são apresentados na Tabela 1. Nesse sentido, percebe-se que no estado de Goiás, a grande maioria deles tem como principal atividade a pecuária (89\%), seguida da agricultura (74\%), com os maiores números de citações. Isso também significa que grande parte dos pecuaristas também são agricultores. Poucos estão ligados as atividades de aquicultura, pescaria, artesanatos, extrativismo, turismo rural, silvicultura, entre outras.

Tabela 1 - Agricultores familiares do estado de Goiás em 2016, de acordo com a emissão de DAPs - por grupo e tipo de atividade

\begin{tabular}{llllll}
\hline Principal atividade & B & V & Total & B / Total & \% do Total \\
\hline Pecuarista & 259 & 5054 & 5313 & $4,9 \%$ & $89,6 \%$ \\
Agricultor & 318 & 4066 & 4384 & $7,3 \%$ & $74,0 \%$ \\
Aquicultor & 4 & 65 & 69 & $5,8 \%$ & $1,2 \%$ \\
Pescador & 2 & 25 & 27 & $7,4 \%$ & $0,5 \%$ \\
Artesão & 0 & 8 & 8 & $0,0 \%$ & $0,1 \%$ \\
Extrativista & 7 & 7 & 14 & $50,0 \%$ & $0,2 \%$ \\
Silvicultor & 0 & 7 & 7 & $0,0 \%$ & $0,1 \%$ \\
Turismo Rural & 0 & 11 & 11 & $0,0 \%$ & $0,2 \%$ \\
Outra & 14 & 61 & 75 & $18,7 \%$ & $1,3 \%$ \\
\hline Total - citações & $\mathbf{5 9 0}$ & $\mathbf{9 2 4 3}$ & $\mathbf{9 8 3 3}$ & $\mathbf{6 , 0} \%$ & - \\
\hline Total - agricultores & 373 & 5554 & 5927 & & - \\
\hline
\end{tabular}


De acordo com o relatório anual de atividades da Emater em 2016, a ATER é mais demandada pelas atividades agropecuárias, correspondendo a $66 \%$ (78.879) dos atendimentos realizados. Destes, 67\% e 33\% estão relacionadas à prática de pecuária e agricultura, respectivamente. Em relação à pecuária, as atividades de bovinocultura de leite (73\%) e de corte (26\%) são as que demandam maior foco da ATER.

Vale ressaltar que a tabela anterior e as próximas não apresentam o número total de agricultores familiares, mas aqueles que tiveram DAP emitida no ano de referência - este é um dos critérios de enquadramento do agricultor familiar (Tabela 2). A DAP tem data de validade de dois anos, a contar da data de emissão. Isso garante que o número de DAPs emitidas representa bem a demanda potencial de recursos a serem tomados pelos agricultores familiares.

Tabela 2 - DAPs emitidas em 2016 pela Emater - por tipo de uso da propriedade

\begin{tabular}{llll}
\hline Condição de uso & Número & Área total & Média de área \\
\hline Proprietário & 3913 & $149.112,07$ & 38,11 \\
Arrendatário & 1068 & $48.945,40$ & 45,83 \\
Comodatário & 326 & $15.566,93$ & 47,75 \\
Posseiro & 284 & $10.350,68$ & 36,45 \\
Assentado pelo PNRA & 278 & $9.974,67$ & 35,88 \\
Outros & 35 & 831,55 & 23,76 \\
Parceiro & 17 & 766,16 & 45,07 \\
Uso Coletivo & 6 & 465,18 & 77,53 \\
\hline Total & $\mathbf{5 9 2 7}$ & $\mathbf{2 3 6 . 0 1 2 , 6 4}$ & $\mathbf{3 9 , 8 2}$ \\
\hline
\end{tabular}

Fonte: Emater; Elaborada pelos autores (2017).

A Tabela 2 apresenta outra informação importante sobre a emissão de DAPs, já que está vinculada à condição de uso da propriedade. Em 2016, das 5.927 DAPs, quase dois terços foram elaboradas para os próprios donos da propriedade, que possuíam uma área média de 38,1 ha. O segundo maior grupo de DAPs foi para arrendatários. Apenas esses tipos representaram mais de $80 \%$ das DAPs emitidas pela Emater no ano de 2016. Esse é importante para explicar o uso de garantias na tomada de crédito. 
Desses agricultores, 39,2\% possuíam $1^{\circ}$ grau incompleto, $14,7 \%$ tinham $1^{\circ}$ grau completo, $20 \%$ o ensino médio e menos de $5 \%$ tinham curso superior. Essa informação pode explicar a dificuldade dos agricultores de acessarem as Declarações de Aptidão e, consequentemente, a tomada de crédito rural, especificamente à linha PRONAF. Ademais, mostra a importância do extensionista/técnico da Emater para o agricultor familiar.

Ainda, no levantamento feito nos sistemas da Emater, em 2016, as atividades mais exercitadas pelos extensionistas foram aquelas ligadas ao crédito rural, seja na elaboração de DAP ou na elaboração de projetos de crédito. Entre os projetos elaborados pelos técnicos da Emater, percebe-se uma grande heterogeneidade territorial na prestação de serviços. Algumas unidades regionais chegam a elaborar dez vezes mais projetos do que outras (Figura 1). Do total de DAPs emitidas em 2016, aproximadamente, $56 \%$ foram emitidas pela Emater. 


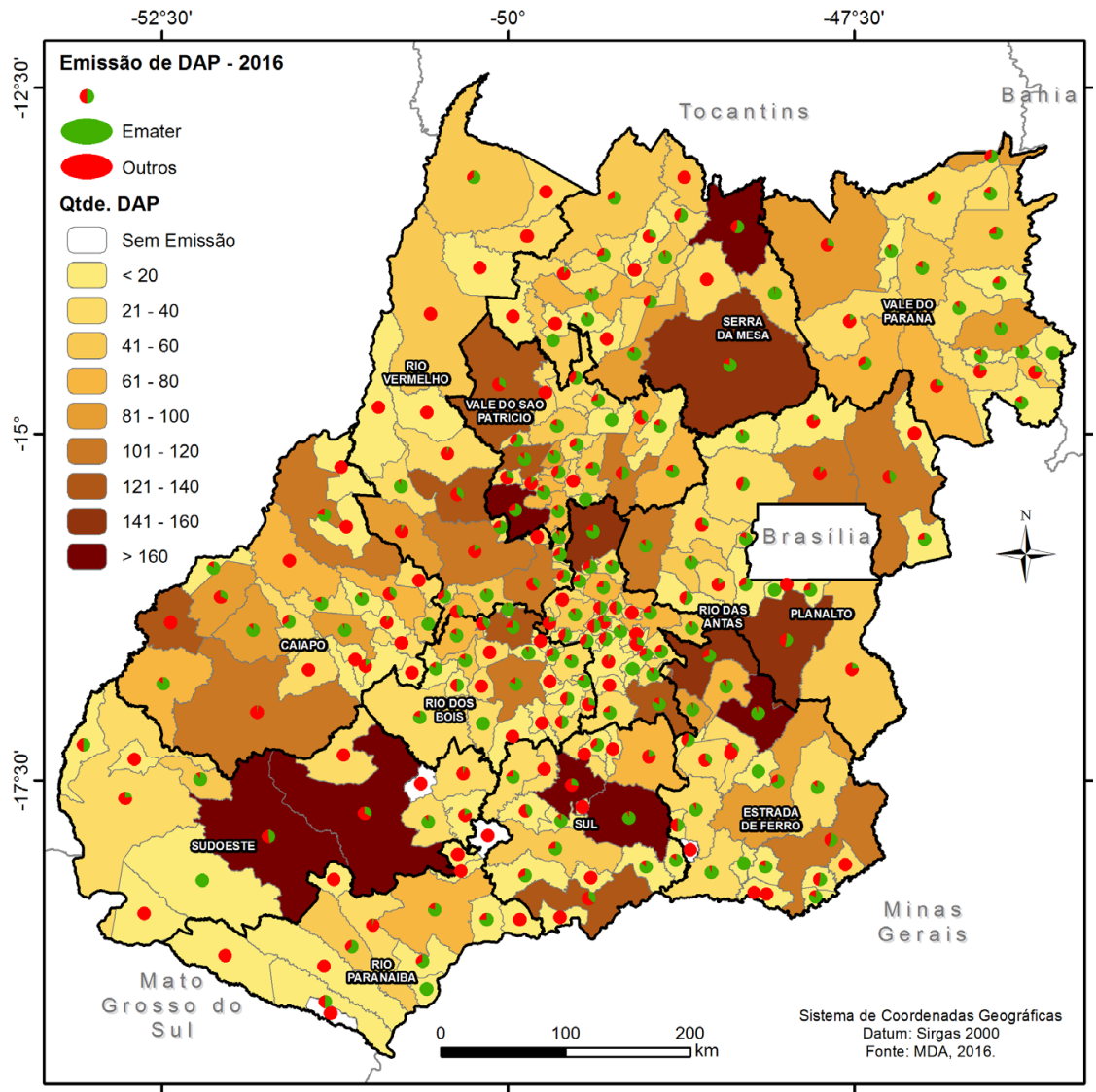

Figura 1 - DAPs emitidas pela Emater e outras entidades no estado de Goiás - 2016

Fonte: Emater; elaborada pelos autores.

Assim, percebe-se a importância da presença física dos escritórios da Emater em cada município do Estado. Atualmente, a Emater está presente em 206 dos 246 municípios do estado de Goiás, estando localizadas nesses, aproximadamente, 95\% da população goiana. Essa presença é importante porque garante a presença do técnico assistente ou extensionista, isto é, a ATER para o agricultor familiar. Ademais, é esse agente que elabora e acompanha os projetos de financiamento rural.

Em termos de Valor Adicionado Bruto da Agropecuária (2014), 85,7\% foi gerado em municípios que possuem unidade da Emater. Do total, 89,0\% 
das DAPs elaboradas em 2016 estão nesses municípios, que emitiram, em média, 47,6 DAPs, enquanto os que não tinham Emater produziram 21,3 DAPs. Em relação ao total financiado pelo PRONAF no estado de Goiás, $87,1 \%$ do valor se concentra em municípios que possuem uma unidade local da Emater. Portanto, é evidente o papel dessa instituição para o desenvolvimento da agropecuária local.

A Tabela 3 também revela a diferença que existe entre as regionais da Emater, pois, enquanto algumas são responsáveis por mais de 90\% dos lançamentos de DAPs emitidas pela própria instituição, outras não conseguem atingir nem $40 \%$ do total das DAPs elaboradas.

Tabela 3 - Emissão de DAPs e elaboração de projetos pela

Emater em 2016 - por Unidade regional

\begin{tabular}{l|ccc|cccc}
\hline Unidade Regional & $\begin{array}{c}\text { DAP } \\
\text { Total }\end{array}$ & $\begin{array}{c}\text { DAP } \\
\text { Emater }\end{array}$ & $\begin{array}{c}\text { \% DAPs } \\
\text { Emater }\end{array}$ & $\begin{array}{c}\text { Número } \\
\text { de } \\
\text { Contratos }\end{array}$ & $\begin{array}{c}\text { Valor } \\
\text { Total dos } \\
\text { Contratos }\end{array}$ & $\begin{array}{c}\text { Valor Total } \\
\text { da ATER }\end{array}$ & $\begin{array}{c}\% \text { projetos } \\
\text { Emater } / \\
\text { DAPs Emater }\end{array}$ \\
\hline Caiapó & 1087 & 478 & $44,0 \%$ & 313 & 21.648 .602 & 158.505 & $65,5 \%$ \\
Estrada de ferro & 1091 & 838 & $76,8 \%$ & 485 & 28.623 .870 & 210.737 & $57,9 \%$ \\
Planalto & 774 & 389 & $50,3 \%$ & 267 & 25.787 .758 & 137.840 & $68,6 \%$ \\
Rio das Antas & 878 & 616 & $70,2 \%$ & 400 & 78.316 .420 & 204.849 & $64,9 \%$ \\
Rio dos Bois & 701 & 445 & $63,5 \%$ & 142 & 16.591 .552 & 47.123 & $31,9 \%$ \\
Rio Paranaíba & 179 & 89 & $49,7 \%$ & 54 & 4.808 .451 & 49.949 & $60,7 \%$ \\
Rio Vermelho & 1022 & 387 & $37,9 \%$ & 173 & 13.631 .702 & 103.816 & $44,7 \%$ \\
Serra da Mesa & 1012 & 629 & $62,2 \%$ & 590 & 26.591 .093 & 148.083 & $93,8 \%$ \\
Sudoeste & 651 & 265 & $40,7 \%$ & 142 & 7.774 .940 & 76.745 & $53,6 \%$ \\
Sul & 922 & 487 & $52,8 \%$ & 263 & 26.767 .776 & 119.205 & $54,0 \%$ \\
Vale do Paranã & 781 & 465 & $59,5 \%$ & 174 & 12.105 .362 & 195.959 & $37,4 \%$ \\
Vale S. Patrício & 1345 & 839 & $62,4 \%$ & 656 & 30.484 .477 & 246.098 & $78,2 \%$ \\
\hline \multicolumn{1}{c|}{ Total Geral } & $\mathbf{1 0 4 4 3}$ & $\mathbf{5 9 2 7}$ & $\mathbf{5 6 , 8} \%$ & $\mathbf{3 6 5 9}$ & $\mathbf{2 9 3 . 1 3 2 . 0 0 3}$ & $\mathbf{1 . 6 9 8 . 9 0 8}$ & $\mathbf{6 1 , 7 \%}$ \\
\hline
\end{tabular}

Fonte: MDA (2016) e Emater; Elaborada pelos autores (2017).

Ao total, a Emater elaborou projetos que receberam mais de R\$ 293 milhões (85\%), apenas em 2016, do total de R\$ 346 milhões, mostrando, mais uma vez, a sua importância para os agricultores familiares. A Emater arrecadou mais de $\mathrm{R} \$ 1,6$ milhões, equivalente a $0,58 \%$ do valor total financiado (via Emater). De acordo com o Manual do Crédito Rural ${ }^{1}$, pode 
ser cobrado um valor limitado a $2 \%$ no caso de orientação técnica individual (acompanhamento) e de $0,5 \%$ para despesas totais de estudos técnicos isolados (plano ou projeto), avaliação, exame de escrita, perícia e vistoria.

A Tabela 4 mostra que a maior parte da arrecadação $(80,8 \%)$ da Emater foi com a elaboração de projetos de financiamento. Menos de $1 \%$ esteve voltado exclusivamente para o acompanhamento, e o restante $(18,2 \%)$ foi para a elaboração e acompanhamento dos projetos financiados.

Tabela 4 - Valor contratado em 2016 - por banco, modalidade e finalidade

\begin{tabular}{|c|c|c|c|c|c|c|c|}
\hline $\begin{array}{l}\text { Modalidade/ } \\
\text { Finalidade }\end{array}$ & Bradesco & Sicredi & BB & CEF & Itaú & Sicoob & Total \\
\hline \multicolumn{8}{|c|}{ Investimento } \\
\hline Acompanhamento & & & 1.977 .134 & & & & 1.977 .134 \\
\hline Elaboração & 657.851 & 100.000 & 113.439 .915 & 2.911 .702 & & 430.000 & 117.539 .469 \\
\hline Elaboração e Acomp. & 454.079 & 390.555 & 37.535 .838 & & & 89.600 & 38.470 .071 \\
\hline Investimento Total & 1.111 .930 & 490.555 & 152.952 .887 & 2.911 .702 & & 519.600 & 157.986.674 \\
\hline \multicolumn{8}{|c|}{ Custeio Pecuário } \\
\hline Acompanhamento & & & 662.925 & & & & 662.925 \\
\hline Elaboração & 452.300 & 145.913 & 88.703 .422 & 1.472 .353 & 19.101 .030 & 1.220 .780 & 111.095 .798 \\
\hline Elaboração e Acomp. & & & 1.551 .937 & & & & 1.551 .937 \\
\hline Custeio Pecuário Total & 452.300 & 145.913 & 90.918 .284 & 1.472 .353 & 19.101 .030 & 1.220 .780 & 113.310 .660 \\
\hline \multicolumn{8}{|c|}{ Custeio Agrícola } \\
\hline Acompanhamento & & & 106.996 & & & & 106.996 \\
\hline Elaboração & 443.100 & & 7.433 .578 & 351.910 & & 216.000 & 8.444 .588 \\
\hline Elaboração e Acomp. & & & 7.188 .363 & 6.226 .604 & & 41.682 & 13.456 .648 \\
\hline Custeio Agrícola Total & 443.100 & & 14.728 .937 & 6.578 .514 & & 257.682 & 22.008 .233 \\
\hline \multicolumn{8}{|c|}{ Comercialização } \\
\hline Acompanhamento & & & & 500 & & & 500 \\
\hline Elaboração & & & 70.551 & & & & 70.551 \\
\hline Comercialização Total & & & 70.551 & 500 & & & 71.051 \\
\hline Total Geral & 2.007.330 & 636.468 & 258.670 .659 & 10.963 .069 & 19.101.030 & 1.998 .062 & 293.376.618 \\
\hline
\end{tabular}


A respeito da finalidade desses recursos, mais de $\mathrm{R} \$ 157$ milhões, i.e. 53,9\% do total, foram para investimentos, enquanto $\mathrm{R} \$ 113$ milhões $(38,6 \%)$ destinaram-se ao custeio pecuário e R\$ 22 mil (7,5\%) para o custeio agrícola, sendo menos de $1 \%$ para a comercialização. Por fim, esse valor foi majoritariamente $(88,2 \%)$ financiado pelo Banco do Brasil, sendo este banco, o maior responsável pela política de crédito rural no Brasil.

\section{Situação atual do PRONAF em Goiás}

Os recursos do PRONAF alcançaram R $\$ 28,9$ bilhões em 2016, sendo que a Poupança Rural representou cerca de 40\% desse montante, os Fundos Constitucionais (FCO, FNE e FNO) mais de 20\%, Instrumentos Híbridos de Capital e Dívida (IHCD) acima dos 17\%, o Fundo de Amparo do Trabalhador (FAT) aproximadamente 10\%, além dos mais de $10 \%$ dos recursos que se enquadram no MCR 6.2, descritos no Manual como créditos obrigatórios.

Para ter acesso aos recursos destinados ao programa, o produtor necessita da DAP, emitida gratuitamente na Emater ou Sindicato dos Trabalhadores Rurais. Depois, o produtor solicita um Projeto Técnico de Financiamento, elaborado por um dos técnicos da extensão rural ou assessor de crédito que compõe o quadro de servidores destas entidades. Todos esses documentos são encaminhados ao agente financeiro (Banco do Brasil, Banco do Nordeste, Banco da Amazônia) para a contratação do crédito pleiteado. Pescadores artesanais, pequenos aquicultores, silvicultores, integrantes de comunidades quilombolas rurais, entre outros, podem se beneficiar do PRONAF.

Os investimentos aplicados em Goiás ultrapassam os R $\$ 4,8$ bilhões desde o início do programa, com mais de 230 mil contratos. Somente em 2015, foram aplicados no Estado R 344 milhões em 10,5 mil operações e, em 2016, mais de R 346 milhões em 6,5 mil operações. No Centro-Oeste, ao todo, foram investidos $\mathrm{R} \$ 1,9$ bilhões em mais de 40 mil financiamentos nesse biênio, como demonstra a Tabela 5 . 
Tabela 5 - PRONAF em Goiás, 2002 a 2016 (R\$ mil)

\begin{tabular}{cccccc}
\hline ANO & Contratos & Variação (\%) & Valor (R\$ mil) & Variação (\%) & $\begin{array}{c}\text { Tíquete Médio } \\
\text { (R\$ mil) }\end{array}$ \\
\hline 2002 & 642 & - & 12.878 & - & 20,06 \\
2003 & 695 & 8,26 & 16.165 & 25,52 & 23,26 \\
2004 & 20.977 & $2.918,27$ & 270.542 & $1.573,63$ & 12,90 \\
2005 & 21.012 & 0,17 & 280.150 & 3,55 & 13,33 \\
2006 & 25.046 & 19,20 & 320.923 & 14,55 & 12,81 \\
2007 & 25.092 & 0,18 & 309.099 & $-3,68$ & 12,32 \\
2008 & 24.667 & $-1,69$ & 358.265 & 15,91 & 14,52 \\
2009 & 25.462 & 3,22 & 579.628 & 61,79 & 22,76 \\
2010 & 23.622 & $-7,23$ & 571.045 & $-1,48$ & 24,17 \\
2011 & 21.466 & $-9,13$ & 548.602 & $-3,93$ & 25,56 \\
2012 & 15.364 & $-28,43$ & 412.830 & $-24,75$ & 26,87 \\
2013 & 6.528 & $-57,51$ & 185.771 & $-55,00$ & 28,46 \\
2014 & 4.663 & $-28,57$ & 279.256 & 50,32 & 59,89 \\
2015 & 10.573 & 126,74 & 344.409 & 23,33 & 32,57 \\
2016 & 6.549 & $-38,06$ & 346.571 & 0,63 & 52,92 \\
\hline Total & 232.358 & & 4.836 .134 & & $\mathbf{2 5 , 4 9}$ \\
\hline
\end{tabular}

Fonte: Ministério da Integração Nacional / CONDEL/SUDECO / Banco do Brasil; elaborada pelos autores (2017).

Observação: Valores atualizados pelo IPCA, posição 12/2016.

Os recursos contratados em 2016 concentram-se na agricultura e pecuária. A pecuária se destaca representando 96,8\% de todos os recursos financiados pelo PRONAF em 2016, chegando a um volume de R\$ 335 milhões em mais de 6,4 mil contratos; já a agricultura teve quase R\$ 11 milhões dos recursos disponíveis aplicados em 209 operações (Tabela 6). 
Tabela 6 - PRONAF em Goiás, 2016 (R\$ mil) - por atividade e mesorregião

\begin{tabular}{cccccccc}
\hline Natureza & $\begin{array}{c}\text { Centro } \\
\text { Goiano }\end{array}$ & $\begin{array}{c}\text { Leste } \\
\text { Goiano }\end{array}$ & $\begin{array}{c}\text { Noroeste } \\
\text { Goiano }\end{array}$ & $\begin{array}{c}\text { Norte } \\
\text { Goiano }\end{array}$ & $\begin{array}{c}\text { Sul } \\
\text { Goiano }\end{array}$ & TOTAL & $\%$ \\
\hline Agricultura & 5.559 & 1.375 & - & 563 & 3.441 & 10.938 & $3,2 \%$ \\
Comércio & - & - & - & - & - & - & $0,0 \%$ \\
Diversos & 58 & 15 & - & - & - & 73 & $0,0 \%$ \\
Extração Mineral & - & - & - & - & - & - & $0,0 \%$ \\
Fabricação Indústria & 20 & - & - & - & - & 20 & $0,0 \%$ \\
Pecuária Bovina Corte & 27.647 & 4.552 & 25.667 & 37.297 & 19.716 & 114.880 & $33,1 \%$ \\
Pecuária Bovina Leite & 79.877 & 9.165 & 32.099 & 11.755 & 86.834 & 219.730 & $63,4 \%$ \\
Pecuária Diversa & 471 & 213 & - & 95 & 151 & 930 & $0,3 \%$ \\
Serviços & - & - & - & - & - & - & $0,0 \%$ \\
\hline Total Geral & $\mathbf{1 1 3 . 6 3 2}$ & $\mathbf{1 5 . 3 2 1}$ & $\mathbf{5 7 . 7 6 6}$ & $\mathbf{4 9 . 7 1 0}$ & $\mathbf{1 1 0 . 1 4 2}$ & $\mathbf{3 4 6 . 5 7 1}$ & $\mathbf{1 0 0 , 0} \%$ \\
\hline
\end{tabular}

Fonte: Ministério da Integração Nacional / CONDEL/SUDECO / Banco do Brasil; elaborada pelos autores (2017).

Em termos territoriais, apenas duas mesorregiões, Centro e Sul, acumularam mais de $64,5 \%$ de todo o recurso distribuído em 2016 no Estado. As outras mesorregiões, mais carentes em termos econômicos, receberam o restante do recurso. A Figura 2 apresenta a distribuição de financiamentos em 2016, com destaque para a divisão regional da Emater.

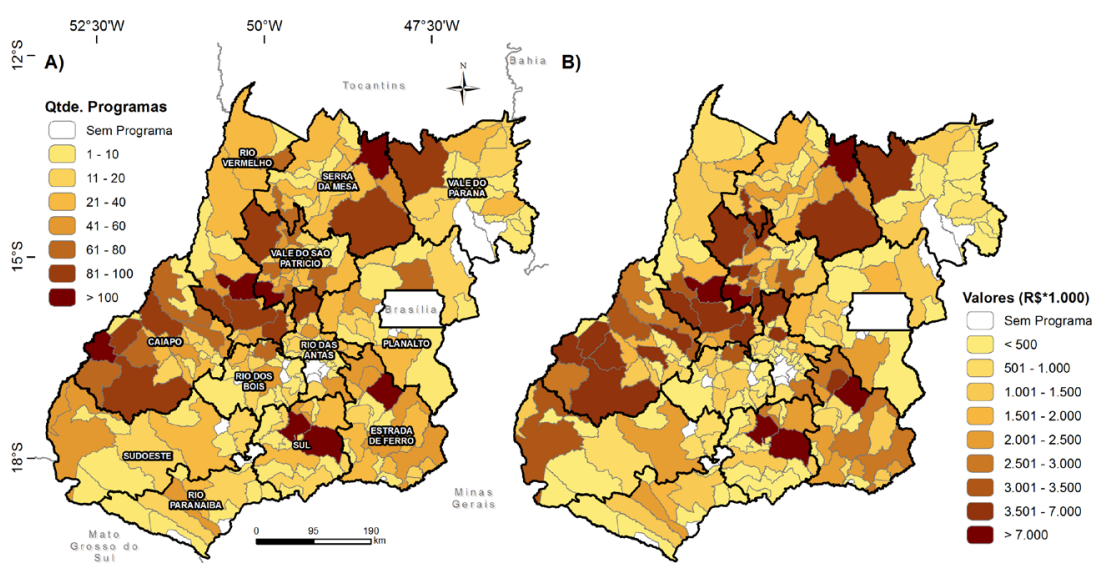

Figura 2 - Distribuição do número de operações (A) e valores (B) do PRONAF em Goiás $\square 2016$ Fonte: Banco do Brasil (2016); Elaborado pelos autores (2017). 
O Gráfico 1, baseado na regressão de mínimos quadrados ordinários, mostra à esquerda uma correlação positiva e estatisticamente significante entre o PIB municipal agropecuário (2014) e o valor recebido pelo PRONAF (2016). O gráfico da direita, por sua vez, mostra a correlação positiva entre os recursos do FCO recebidos por cada município nas linhas de crédito e Desenvolvimento Rural, voltada para o grande agricultor, e o PRONAF. Além da correlação ser estatisticamente significante a 1\%, o gráfico mostra que para cada $\mathrm{R} \$ 100$ voltado para o Desenvolvimento Rural, há um recebimento de R\$ 7,77 para o PRONAF. Assim, ambos os casos evidenciam que a distribuição de recursos do PRONAF teve o efeito positivo no valor adicionado na agropecuária.

Gráfico 1 - Relação entre PIB agropecuário (eixo Y) e PRONAF (eixo X) por município - gráfico à esquerda; distribuição municipal de FCO, linha Desenvolvimento Rural (X) e PRONAF (Y) - direita
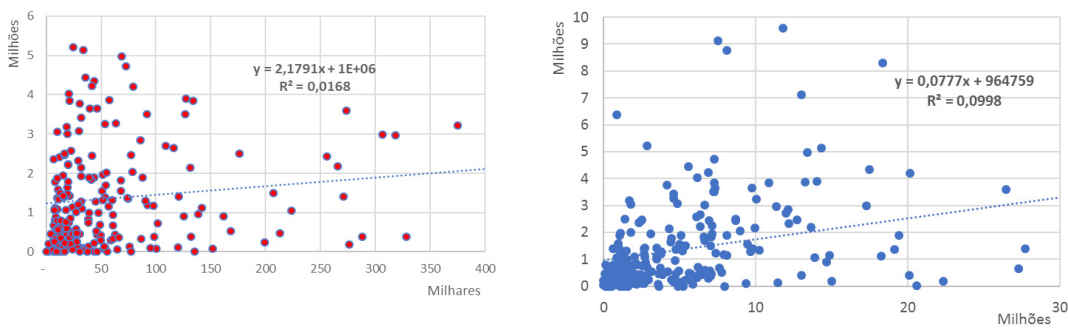

Fonte: Banco do Brasil (2016); elaborado pelos autores.

Todo esse investimento tem uma série de externalidades (positivas e negativas). $\mathrm{O}$ crédito permite tecnificação da produção, poupadora de mão de obra, que contribui para o êxodo rural, especialmente para os grandes centros urbanos, a exemplo de Goiânia, Anápolis e Brasília. Por outro lado, o maior rendimento por área do pequeno produtor, principal ofertante de alimentos (não commodities), contribui para uma maior oferta de produtos que vão para as mesas dos brasileiros, a exemplo das hortaliças, frutas, arroz e feijão. 


\section{Considerações finais}

Os estudos anteriores investigaram os efeitos do PRONAF em diversos Estados do Brasil, contudo, nenhum deles aprofundou especificamente no caso goiano. Portanto, esta pesquisa trouxe uma nova compreensão, além de insights, sobre o funcionamento da linha de crédito em Goiás. Criado na década de 90, o PRONAF se tornou relevante intervenção estatal, que aprofundou a inserção econômica do agricultor familiar no meio rural.

A falta de assistência técnica ou a sua baixa qualidade influenciam negativamente na geração de renda pelos tomadores do PRONAF. A ausência de unidades locais e o baixo número de técnicos para dar orientação explicam essa situação. Os dados mostram que os recursos são concentrados em termos espaciais, isto é, para que a política possa mitigar a desigualdade regional é necessário que haja maior diversificação territorial na distribuição de recursos. As duas mesorregiões mais ricas do Estado, a Centro e a Sul, recebem mais de 64\% dos recursos do PRONAF.

Em 2016, mais de 70\% dos agricultores familiares não possuíam nem o Ensino Médio completo. Assim, a baixa escolaridade é outro fator que revela a importância do extensionista/técnico da Emater, que presta um importante papel na introdução de tecnologias e, até mesmo, conhecimentos básicos para o agricultor familiar.

Outra grande contribuição da ATER diz respeito à elaboração e o acompanhamento dos projetos de financiamento, especialmente no primeiro caso, onde existe a obrigatoriedade de participação do assistente técnico. Mais de 80\% dos recursos arrecadados pela Emater são referentes a esta atividade. Ressalta-se também que a maior parte dos financiamentos tem a finalidade de investimento, estando o custeio em segundo plano.

Por fim, há ressalva de que diversas questões não foram tratadas, tais como a inadimplência, não abordada ante a indisponibilidade de informações. Futuramente, pretende-se aplicar metodologias de outros estudos, a exemplo dos Fundos Constitucionais, que não necessariamente têm validade para o PRONAF, por incorporarem outras linhas de financiamento. Além disso, também se deve apresentar estratégias de atuação do financiamento de modo a maximizar sua eficiência e contribuir para o desenvolvimento regional. Ademais, é fundamental investigar sua distribuição territorial, com destaque para a formação de clusters. 


\section{Nota}

1 Capítulo: Condições Básicas - 2; Seção: Despesas - 4.

\section{Agradecimento}

Agradecimentos aos técnicos da Emater pelas contribuições durante o processo de revisão do trabalho. O primeiro autor agradece o apoio da Fundação Nacional de Desenvolvimento do Ensino Superior (FUNADESP).

\section{Referências}

BRASIL. Banco Central do Brasil. Manual do Crédito Rural. [on-line]. Disponível em:< https://www3.bcb.gov.br/mcr>. Acesso em: 8 nov. 2017.

. Lei $n^{\circ} 4.829$, de 5 de novembro de 1965. Institucionaliza o crédito rural. Disponível em:< http://www.planalto.gov.br/ccivil_03/leis/L4829.htm>. Acesso em: 8 nov. 2017.

. Decreto no 1946, de 28 de junho de 1996. Cria o Programa Nacional de Fortalecimento da Agricultura Familiar - PRONAF, e dá outras providências. Disponível em: < http://www.planalto.gov.br/ccivil_03/decreto/d1946.htm>. Acesso em: 8 nov. 2017.

. Decreto no 3.200, de 6 de outubro de 1999. Disponível em: < http:// www.planalto.gov.br/ccivil_03/decreto/d3200.htm>. Acesso em: 8 nov. 2017.

. Decreto no 3.508, de 14 de junho de 2000. Dispõe sobre o Conselho Nacional de Desenvolvimento Rural Sustentável - CNDRS, e dá outras providências. Disponível em: < http://www.planalto.gov.br/ccivil_03/decreto/ d3508.htm>. Acesso em: 8 nov. 2017.

BRASIL. Lei no 12.188, de 11 de janeiro de 2010. Institui a Política Nacional de Assistência Técnica e Extensão Rural para a Agricultura Familiar e Reforma Agrária - PNATER e o Programa Nacional de Assistência Técnica e Extensão Rural na Agricultura Familiar e na Reforma Agrária - PRONATER, altera a Lei no 8.666, de 21 de junho de 1993, e dá outras providências. Disponível em: < portal.mda.gov.br/o/6421940>. Acesso em: 8 nov. 2017.

. MMA. Ministério do Meio Ambiente. Mapeamento do Uso e Cobertura do Cerrado: Projeto TerraClass Cerrado 2013. Brasília: MMA, 2015.

. Portaria $n^{o}$ 234, de 04 de abril de 2017. Disponível em: < http:// WwW.mda.gov.br/sitemda/sites/sitemda/files/user_img_1754/PORTARIA\%20 N\%C2\%BA\%20234\%2C\%20DE\%2004\%20DE\%20ABBRIL\%20DE\%202017.pdf>. Acesso em: 8 nov. 2017.

CARDOSO, R. E. P. (Coord.). Governo de Goiás. Secretaria de Estado de Gestão e Planejamento. Plano Plurianual 2016-2019. Goiás: Segplan, 2016. Disponível em: 
<http://www.sgc.goias.gov.br/upload/arquivos/2016-08/ppa-2016-20191.pdf>. Acesso em: 8 nov. 2017.

CARNEIRO, M. J. Política pública e agricultura familiar: uma leitura do PRONAF. Estudos Sociedade e Agricultura, n. 8, abr.1997.

EUSÉBIO, G.; MAIA, A.; SILVEIRA, R. Impact of microcredit on small-farm agricultural production: evidence from Brazil. Agricultural \& Applied Economics Association Annual Meeting, Boston, jul./ago. 2016.

FEIJÓ, R. Um estudo quantitativo dos subsídios implícitos nas Operações de crédito do PRONAF. Pesquisa e Planejamento Econômico (PPE), v. 44, n. 2, ago. 2014.

GAZOLLA, M.; SCHNEIDER, S. Qual "Fortalecimento" da Agricultura Familiar? Uma análise do PRONAF crédito de custeio e investimento no Rio Grande do Sul. Revista de Economia e Sociologia Rural (RESR), Piracicaba, v. 51, n. 1, p. 4568, jan./mar. 2013.

GUANZIROLI, C. E. PRONAF dez anos depois: resultados e perspectivas para o desenvolvimento rural. Revista de Economia e Sociologia Rural. Rio de Janeiro, v. 45, n. 2, p. 301-328, abr./jun. 2007.

GUILHOTO, J. et al. A Importância do Agronegócio Familiar no Brasil. Revista de Economia e Sociologia Rural, Brasília, v..44, n.3, jul./set. 2006.

IBGE. Instituto Brasileiro de Geografia e Estatística. Produção Agrícola Municipal (PAM). 2015. Disponível em:< https://ww2.ibge.gov.br/home/estatistica/ economia/pam/2015/default.shtm>. Acesso em: 8 nov. 2017.

.Pesquisa Pecuária Municipal (PPM). 2015. Disponível em:< https://sidra. ibge.gov.br/pesquisa/ppm/tabelas/brasil/2016>. Acesso em: 27 nov. 2017.

MELO, L.; RESENDE FILHO, M. Determinantes do Risco de Crédito Rural no Brasil: Uma Crítica às Renegociações da Dívida Rural. Revista Brasileira de Economia, Rio de Janeiro, v. 71, n. 1, p. 67-91, jan./mar. 2017.

NAVARRO, Z. A agricultura familiar no Brasil: entre a política e as transformações da vida econômica. In: GASQUES, J.; VIEIRA FILHO, J.; NAVARRO, Z. (Org.). Agricultura brasileira: desempenho, desafios e perspectivas. Brasília: IPEA, 2010

PEREIRA, A.; DUARTE, H. Síntese Histórica e Analítica de Extensão Rural em Goiás. In: PEREIRA, A. (Org.). Agricultura de Goiás: Análise e Dinâmica. Goiânia, UCG, 2004.

QUEIROZ, C. C. Rudimentos da História do Trabalho Social da Extensão Rural em Goiás. In: PEREIRA, A. (Org.). Agricultura de Goiás: Análise e Dinâmica. Goiânia, UCG, 2004. p. 957.

OLIVEIRA, M. M. A conjugação do crédito rural à assistência técnica no Brasil: análise da experiência do sistema brasileiro de assistência técnica e extensão rural. In: Caderno de Difusão Tecnológica, EMBRAPA, jan/abr, 1984.

RIBEIRO, J. P. A saga da Extensão Rural em Minas Gerais. São Paulo: Annablume, 2000. 
SANTANA, E. P.; MIZIARA, F. Extensão Rural no Estado de Goiás: Produção Familiar e Modernidade Reflexiva. IN: XLIV CONGRESSO BRASILEIRO DE ECONOMIA E SOCIOLOGIA RURAL, 2006, Fortaleza. Anais... Fortaleza: UFC, p. 1-13, 2006.

SILVA, J. G. O Novo Rural Brasileiro. Revista Nova economia, Belo horizonte, v. 7, n.1, p. 43-81, maio 1997.

SOUZA, C.; CAUME, D. Crédito Rural e Agricultura Familiar no Brasil. In: XLVI Congresso da Sociedade Brasileira de Economia, Administração e Sociologia Rural, 2008, Acre. Anais... Rio Branco, jul. 2008.

SOUZA, S. B.; OLIVEIRA, M. L. R.; COELHO, F. M. G. A Atuação dos Clubes 4-S em Minas Gerais e a Ideia de Juventude Rural na Emater/MG. Holos, ano 32, v. 1, p. 142-152, 2016.

VITAL, T.; MELO, A. O Agroamigo em Pernambuco: alguns resultados. Revista Econômica do Nordeste, Fortaleza, v. 46, suplemento especial, p. 123-138, jul. 2015.

Guilherme Resende Oliveira - possui graduação, mestrado e doutorado em Economia pela Universidade de Brasília. Atualmente é Gerente da Gerência de Inteligência Territorial da Agência Goiana de Assistência Técnica, Extensão Rural e Pesquisa Agropecuária. Professor da Alfa e do Instituto de Pós-Graduação e Graduação.

Fernando Moreira de Araújo - possui graduação e mestrado em Geografia pela Universidade Federal de Goiás. Doutorado em Ciências Ambientais pela mesma Universidade. Atualmente é assessor especial na Gerência de Inteligência Territorial da Agência Goiana de Assistência Técnica, Extensão Rural e Pesquisa Agropecuária.

Carlos César de Queiroz - possui graduação em Engenharia Agronômica pela Universidade Federal de Lavras. Mestrado em Administração Rural pela UFLA. Atualmente é Técnico da Gerência de Inteligência Territorial da Agência Goiana de Assistência Técnica, Extensão Rural e Pesquisa Agropecuária.

\section{Contribuições dos autores}

Todos os autores ofereceram substanciais contribuições científicas e intelectuais ao estudo. As tarefas de concepção e design do estudo, preparação, tabulação e análise dos dados e redação do manuscrito, bem como a revisão crítica, foram desenvolvidas em grupo. Os autores foram responsáveis pelo desenvolvimento teórico-conceitual; pela aquisição de dados, interpretação e análise; e pelos procedimentos técnicos e tradução do artigo. Dessa forma, o primeiro autor, a partir da pesquisa 
de doutorado, concebeu o estudo, a metodologia, análise estatística e os resultados/discussão; o segundo autor, por sua vez, organizou a base de dados, a produção dos mapas em ambiente SIG/Geoprocessamento e desenvolvimento dos resultados/discussão; e o terceiro autor auxiliou no levantamento bibliográfico base do estudo, desenvolvendo os tópicos sobre a ATER e PRONAF, como também contribuiu no desenvolvimento dos resultados/discussão.

Recebido para publicação em 02 de setembro de 2017 Aceito para publicação em 15 de outubro de 2017 